has since been signed by the governor. The board created by this act is to be non-partisan and to consist of five membors, but will not have control over corrective institutions.

L. C. TAYLoR, Springfield, Ill.

Chairman Committee on Medical Legislation, Illinois Medical Society.

\section{A Misquotation from Bishop Fallows Acknowledged}

To the Editor:-In an article entitled, "The General Practitioner and the Functional Nervous Diseases," published in The Journal (Jan. 9, 1909, lii, 87) I quoted some sentences from "Health and Happiness" by Samuel Fallows, D.D. These sentences were taken from the New York Evening Sun, in which they appeared in quotation marks. Bishop Fallows has written to me to say that the sentences making up the quotation are taken from various portions of his book; that is, they are taken out of the proper context. I regret that I did not verify the quotation before the article was published.

Joser'h Colins, New York.

\section{Queries and Minor Notes}

Avonymous Communicatrons will not be noticed. Queries for this column must be accompanied by the writer's name and address, but the request of the writer not to publish name or address will be faithfully observed.

\section{DISPOSAL OF GARBAGE AND FILTRATION OF WATER-} SUPPLY

To the Editor:-Please tell me where I can obtain any information, applicable to a city of 30,000 inhabitants, in regard (1) to modern methods of garbage disposal, and (2) to city filtration of
water-supply.

$$
\text { City Health Commissioner, Rock Island, III }
$$

Axswer.-1. Modern methods of garbage disposal are clearly de scribed in two papers in the Transactions of the American Publio Health Association for 1901 (Vol, xxvii). These are "Refuse D:sposal in Boston," by H. W. Hill, p. 186, and "Refuse Disposal in the District of Columbia," by W. C. Woodward, p. 194. An especially raluable summary also appears in the same publication for 1903 (Vol. xxix), entitled "Some Statistics of Garbage Disposal for the Larger American Cities in 1902," by C-E. A Winslow and P. Hansen. The last named paper gives valuable data regarding cost in this country and abroad, a bibliography of 27 titles, and a classified list of cities using different processes (further information could doubtless be obtained from the municipal authorities if desired). The facts stated in the papers cited seem to justify the conclusion. "that separation of waste materials is neither economical nor desirable, that the cremation of mixed refuse appears to be the most generally satisfactory process and that this cremation may be best accomplished in furnaces of the English type."

2. Three of the best books in English on water filtration are "The Filtration of Water-Supplies," by Allen Hazen, "Clear Water and How to Get It," by the same author, and "Water and Its Purification," by Samuel Rideal. The two first-named are published by John Wiley and Sons, the last by J. B. Lippincott; all are procurable through your local booksellers.

STEREOSCOPY WITHOUT A STEREOSCOPE

To the Editor:-It occurred to me that stereoscopic lliustrations of steps in operative procedures, tumor's, etc., could be more generally used than they are now. I have noticed that, with only a little practice, one can get the stereoscopic effect from a stereoscopic illustration, without the use of a stereoscope. Hold the stereogram before the eyes at a distance of 12 to 26 Inches; look at the white perpendicular line up the middle; gazing not too you persist, a dissolving effect takes place and the single object stands out clear in perspective. The use of such illustrations in our journals and surgical works has many obvious advantages and will appeal to every scientific and sound-eyed physician. This is merely a practical application of an old physiologic fact. Ivan I. Yoder, M.D., Cleveland, Ohio.

\section{THE CAMMIDGE REACTION} To the Editor:-Please give information in regard to the pan-
creatic reaction of Cammidge.

ANSWER.-The pancreatic reaction of Cammidge was described in The Journal, Aug. 22, 1908, li, 691. Opinions are still divided as to its clinical value, although the bulk of evidence is in favor of the view that, while it is not pathognomonic, it is a valuable diagnostic ald.

\section{The Public Service}

\section{Army Changes}

Memorandum of changes of stations and duties of medical officers,

Schmitter, Ferdinand, 1st lieut., ordered to St. Louis, Mo, for emporary duty in charge of the Medical Supply Depot.

Truby, Albert E., major, ordered to take charge of chief surgeon's office, San Francisco, Cal., during the absence of Major James M. Kennedy on inspection tour.

Dale, Frederick A., capt., granted leave of absence for 14 days. Foster, Charles L., capt., ordered from San Francisco, Cal., to Washington, D. C., in charge of an escort to insane patients.

Perley, Harry O., col., announced as chief surgeon, Department of the Colorado; ordered to inspect posts in that department.

Kiersted, Henry S., capt., granted leave of absence for 1 month. Chamberlain, Weston P., noajor, detailed a member of the board of inedical officers for studying tropical diseases in Philippine slands.

Foster, Charles L., capt., granted leave of absence to July 6 .

O'Day, Sylvester F., 1st lieut., M.R.C., honorably discharged from the service of the United States, his services being no longer

Buchsbaum, Maurice, 1st lieut., M.R.C., ordered to duty with troops marching from Fort $D$. A. Russell, Wyo., to Fort Robinson, eb., instead of 1 st Lieut. Joseph E. Bastion, M.R.C

Tyler, George T., 1st lieut., M.R.C., relleved from duty at time to.sail August 5 th for the Philippine Islands.

Kierluff August 5th for the Philippine Islands. Minn. July 2 , for temporary duty.

McMillan, Clemons W., 1st lieut., M.R.C., granted leave of absence for 2 months, August 20 .

Fisk, Owen C., 1st lieut., M.R.C., ordered to Fort Michle, N. Y., for temporary duty during the week beginning July 12 .

McCown, Thomas B., 1st lieut., M.R.C., ordered to Fort Duchesne, Utah, for temporary duty during the week beginning July 12 .

Pomeroy, William H., contract surgeon, granted leave of absence for 21 days.

Graig, Emmett J., dent.-surg., ordered to Fort Des Moines, Iowa, for 1 month, and thence to Fort Riley, Kan. for 3 months.

Ryan, Edward P. R., dent.-surg., ordered to Fort Mackenzie, Wyo. for 20 days, and thence to Fort $D$. A. Russell, Wyo. for 2 months. Boak, S. Davis, dent.-surg., ordered from vancouver Barracks, Wash., to Fort Lawton, Wash., for duty.

Voorhies, Hugh G., dent.-surg., relieved from duty at Fort Snelling, Minn, and ordered to Jefferson Barracks, Mo., for duty.

Ames, John $R$., dent.-surg., relieved from duty at Jefferson Barracks, Mo., and ordered to Fort Snelling, Minn., for duty. Whinnery, Jean C., dent.-surg., arrived at Fort Egbert, Alaska,
for duty.

\section{Navy Changes}

Changes in Medical Corps, U. S. Navy, for the week ended June

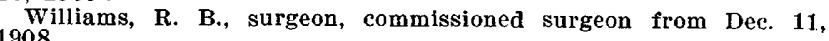

Kennedy, R. M., surgeon, ordered to command the naval hospital, San Juan, $P$. R., sailing from New York, N. Y., about July 24.

Johnson, M. K., surgeon, detached from the Naval Training Station, Narragansett Bay, R. I., July 10 and ordered to the South akota.

Von Wedekind, L. L., surgeon, detached from the South Dakota and ordered home to await orders.

Grove, W. B., surgeon, detached from the Minnesota and ordered to the Naval Training Station, Narragansett Bay, $R$. I.

Alfred, A. R., surgeon, detached from the Wolverine and ordered to the Minnesota.

Dunn, H. A., P. A. surgeon, detached from the Independence, ordered home and granted leave for 2 months.

Webb, U. R. P. A. surgeon, detached from the Naval Hospital, San Juan, P. R., and ordered home to wait orders.

Munger, C. B., asst.-surgeon, ordered to the Naval Training

Robnett, A. H., asst.-surgeon, ordered to duty at Naval Hospital,

Steadman, W. G., asst.-surgeon, detached from the Louisiana and ordered to continue treatment at the Naval Hospital, Nor-
folk, Va. Reed, A. U., asst.-surgeon, ordered to Naval Recruiting Station,

Cohn, I. F., asst.-surgeon, ordered to duty at the Naval Hos. ital, Philadelphia. Woods, E. L., asst.-surgeon, ordered to duty at the Naval Hos-
pital, Annapolis, Md. Olson, G. M., asst.-surgeon, ordered to the Naval Recruiting
Station, Minneapolis.

Shippen, L. P., asst.-surgeon, detached from the Naval Recruiting Station, Minneapolis, and ordered to the Navy Yard, Mare Island, Giltner, H. A., asst.-surgeon, detached from the Naval Training Station, San Francisco, and ordered to the Glacier.

Eytinge, W. O. J., asst.-surgeon, ordered to the Wolverine.

Riker, C. A., asst.-surgeon, detached from the Franklin and

Thomas, G. E., acting asst.-surgeon, detached from duty at the ral Hospltal, Norfolk, Va., and ordered to the Franklin.

Wheeler, L. H., P. A. surgeon, detached from the Hancock and sailing from New York, N. Y., about

Brister, J. M., P. A. surgeon, detached from the Milvoaukee and dered to the Independence.

Jenness, B. F., P. A. stirgeon, detached from the Glacier and ordered to the Milwaukee and to additional duty at the Naval
Hospital, Puget Sound, Wash. 